\title{
The Returns of the Argumentative Turn Bob Jessop
}

Cultural Political Economy Research Centre, Department of Sociology, Lancaster University, Lancaster, UK

This article comments on the argumentative turn as one among many cultural turns. These cover a wide range of (re-)discoveries of the role of semiosis in social life. Indeed, even in a volume with an apparently limited remit within the broad spectrum of cultural turns, we find contributions that develop or deploy, sometimes eclectically, the following analytical approaches: corporeal, deliberative, discursive, epistemic, ethical, hermeneutic, ideational, interpretive, linguistic, metaphorical, narrative, practice, reflexive, rhetorical, semiotic, and visual. These share a theoretical and/or practical interest in the social production of inter-subjective meaning in general and/or through particular semiotic techniques or practices and their translation into communicative practices oriented to, or framing, public policy and its outcomes. Faced with this plethora of approaches, this (meta-)theoretical embarras de richesses, my comment has modest aims. It first reviews some tensions in the overall presentation of different types of turn in the Argumentative Turn Revisited (Fisher and Gottweiss 2012). It then introduces three questions that bear on these tensions and suggests one set of ways to answer them. Of particular importance here is the issue of the evolutionary mechanisms of variation, selection, and retention that shape the effectiveness of arguments. In this context it also reinforces a point made by several contributors about the limits of a one-sided concern with arguments relative to the wider array of factors, actors, and forces that affect the exercise of power. Lastly, it reviews the 'returns' to social theory and practical politics from this turn.

\section{The Argumentative Return Revisited}

The contributions to the present collection cover a wide range of issues and do so from different meta-theoretical, theoretical, empirical, and practical perspectives. Yet an important tension runs through the volume. Does taking an argumentative turn contribute to applied or policy sciences that aim to improve policy-making on one or another instrumental and/or normative ground (for example, more effective, more 
transparent, less manipulative, more deliberative, or more democratic policies)? Is it a way to advance a constructivist, interpretive, or discourse-analytical approach to social scientific inquiry that offers an alternative to rational choice, realist, or technocratic accounts of policy-making? Or, again, is it part of a broader, more critical, even transformational project that aims to critique ideology, show how arguments promote one or another kind of domination, and, thereby, contribute to the development of counter-arguments and eventual challenges to extant forms of domination. There are elements of all three goals across the chapters in this collection and several combine at least two.

The editors' introduction certainly seems to suggest that this trivalency is a positive aspect of the argumentative turn because it opens a productive space for dialogue among competing theories and methods in the social and policy sciences. Several other contributions directly or indirectly suggest ways in which shifting focus from the form and content of policy arguments to themes such as the selectivity of policy forums, unequal access for various classes, social categories, or groups, the shaping of policy frames and personal identities, differential learning capacities, and so on, are important sources of asymmetries in the process of argumentation or deliberation - even before we consider deliberate efforts to distort the process through deception, lying, blackmail, corruption, fraud, and, eventually, force. Moreover, if one turns from public policy-making in presumptively liberal democratic regimes with some measure of public accountability and democratic legitimacy, there is even more scope for systematically structured inequalities in influence over decision-making, resource allocation, and policy externalities. I now address some of these issues.

\section{Effective Arguments, Argumentative Effects}

Social analysis aims to provide explanations that are adequate at the level of intersubjective meaning as well as objective [material] causality. While those who make an argumentative turn do not claim that social life is reducible to argumentation, it is true that arguments can make a difference in many contexts and, in this sense, are causally effective as well as meaningful. Thus problem-definition, deliberation, practical reasoning, rhetoric, and problem-solving are all relevant issues - both in the taken-for-granted framing of policy problems in the case of what Glynos and 
Howarth, following Heidegger, term 'sedimented' situations and in cases where, for whatever cause, the taken-for-granted gets (re-)politicized (Glynos and Howarth 2007, pp. 104-110; this account is broader than the analysis of problematization offered by Howarth and Griggs in the volume under review). Indeed, in such cases the scope for arguments to make a difference is much greater, other things being equal, than when hegemonic or dominant frames have been naturalized. This is especially evident in periods of crisis or other moments of profound disorientation.

While the initial bias in much argumentation analysis is to assess the plausibility of the arguments advanced in a deliberative context, most contributors note that this must be explored in relation to the overall field of intertextuality and its discursive selectivities (including links to more encompassing semiotic frames). Several also note that those engaged in argument will not be equally motivated, equipped, or effective to convey their messages and win support for the conclusions they wish to communicate. This also depends on, for instance, the organization and operation of the mass media, the role of intellectuals in public life, and the structural biases and strategically selective operations of various public and private apparatuses of economic, political, and ideological domination. In addition, Karl Deutsch's definition of power often proves frustratingly relevant: the ability not to have to learn from mistakes (Deutsch 1963, p. 111). Such matters take us beyond argument and specific organizational or institutional genres to the extra-semiotic conditions of plausible arguments and stable semiotic orders and their reinforcement through various structural and technical mechanisms.

Arguments revolve around such questions as: what is the problem (or is there a problem), what can and should be done (if anything), and how should we pursue these goals, policies, or strategies? The analysis of argumentation has much to offer here - although we should be wary of implying that all arguments are carefully constructed and intended for mutual critique and negotiation (cf. the chapter by Dryzek and Hendrike; for a useful guide to the analysis of practical reasoning, see Fairclough and Fairclough 2012). Practical reasoning may be less relevant to private decision-making, especially where opportunism, cynicism, and fatalism prevail; but even private decision-making in networks, organizations, or other collective forces usually draws on practical reasoning in some form. As the analyses in this volume demonstrate, however, the nature of arguments is crucial for the public validation of 
the grounds for interpreting a problem, proposing solutions, distributing the costs and benefits of policies, and justifying this in regard to potential future states of affairs.

Political action is speculative in nature, it is a gamble on probabilistic conclusions, a leap into the future where scientific analysis in terms of true/false is less relevant to questions of unrealized possibilities and feasible policy options than is conjunctural analysis in terms of correct/incorrect readings of a situation (cf. Althusser 1990, pp. 101-105; Debray 1993, p. 106). Parrhēsia (the courage to tell 'truth' to power also arise in this context (see Buchstein and Jörke, this volume); and so is what Glynos and Howarth (2007) and Howarth and Griggs (this volume) identify as the 'fantastic' (fantasmatic, cathectic) element involved in making this 'leap' in reasoning. Moreover, if conclusions are only probabilistic and hence uncertain, the 'leap' is between reasoned but uncertain conclusions and action that 'brackets' uncertainty.

\section{Beyond the Argumentative Turn}

Argument alone cannot transform the world: it must intersect with material (extradiscursive) mechanisms, factors, and actors. The following remarks draw on an earlier article in this journal (Jessop 2009) to explore three questions that bear on the benefits of an argumentative turn:

1. How are the semiotic and extra-semiotic aspects of argumentation related?

2. How do evolutionary mechanisms shape the movement from social construal of policy problems to the social construction of policy solutions?

3. What role can the analysis of argumentation (and related topics) play in denaturalising dominant world images or frames of meaning and thereby revealing (in some cases) their ideological character and their role in reproducing social domination?

The first question is posed in different ways within and across several chapters especially those concerned with questions of the social relations, institutional settings, and technical supports that facilitate/constrain capacities to make effective arguments. The second takes this further by asking why only some of the many competing policy arguments get selected and, eventually perhaps, provide effective 
solutions to policy problems - and so get retained, institutionalized, and, possibly, imitated or transferred elsewhere. This is where the substantive and not merely rhetorical adequacy of solutions to real, that is, underlying problems (as opposed to their symptoms or, indeed, 'manufactured' problems) matters. So do other extrasemiotic mechanisms of selection and retention. Indeed, there is many a slip between the discursive resonance of new arguments and enduring institutional materiality. Elsewhere I have suggested that extra-semiotic factors play a bigger role as one moves from the initial presentation of arguments through the selection of specific arguments to the retention and institutionalization (or sedimentation) of arguments in specific policy frames and policy practices (e.g., Jessop 2009).

Answering the third question poses particularly 'wicked' problems for social analysis. Internal critique is the first, important step in this approach. It explores an argument's flaws and fallacies, identifying incoherence, inconsistencies, contradictions, presences and absences, the voiced and unvoiced, the selection and use of discourses, metaphors, modes of representation, and so forth, the choice of certain genres and styles over others, the nature of the logical and discursive contradictions that are highlighted or overlooked. Internal critique does not simply focus on reasons and justifications. The second step identifies the material and ideal interests that they (are intended to) serve - interests that are partly rooted in the materiality of social relations in specific conjunctures and/or over the longer term and that are partly construed (and, for ideal or other-worldly interests, constructed) through discursive practices (on subjectivities, see in particular Schram's contribution on the subjects of welfare discourse). A third step is to show that these arguments and their associated imaginaries or world images are, indeed, key factors in reproducing systematically structured (and not merely accidental) patterns of exploitation, domination, or oppression. Each step in this chain of analysis is harder and more challenging - but all are essential for the argumentative turn to contribute to normative critique and transformational practice. A good example of such an analysis is Hawkesworth's forensic dissection in this volume of the gendered nature, over many decades, of development discourses, policy, and practices and their role in reproducing a patriarchal, imperial, capitalist order (this volume). 
Looked at more broadly, four forms of selectivity shape the nature and effectiveness of argumentation: discursive selectivities; structural selectivities; agential selectivities; and, fourth, technologies of communication, governance, and governmentality. One aspect of discursive selectivity is the extent to which arguments focus on a limited or broad range of policy alternatives; or, further, look beyond policy choices to more basic questions of institutional design; and, more radically still, consider the basic social forms that reproduce crisis-tendencies and shape the forms that they take. This brings us to structural selectivities, that is, the asymmetries inscribed in particular sets of social relations, from women's micro-credit cooperatives or diverse policy forums through broader institutional settings and the hierarchies of political power (such as the privileged voice of the U.S. President) to global structures of domination (see, respectively, the chapters by Hawkesworth, Dryzek and Hendrike, Schmidt, and Gottweiss, and, on the last point, briefly, the editors' introduction).

Agential selectivities concern the differential capacity of particular agents (individuals or collective) to articulate arguments reasons, whether due to their rhetorical skill or capacities, their ability to engage in transformative learning, or their ability connect particular sets of social relations (e.g., local, national, and global or, again, economic, political, and intellectual). These issues are explored most closely in the respective contributions of Gottweiss, Fischer and Mandell, and Howarth and Griggs (this volume). The latter concerns the differential effectiveness of specific means of advancing arguments and reaching particular audiences, including specific means of communication and governmentality. Particularly interesting on media are Coleman's analysis of the Internet as a transformative deliberative technology and the contribution of Sandercock and Atilli on multi-media technologies in urban planning; and, on new techniques of governmentality, see the remarks of Buchstein and Jörke, all this volume).

\section{Some Conclusions}

The Argumentative Turn Revisited is a landmark in the development of argumentation (or, more broadly, communicative practices) in the analysis of policy discourses and policy-making. The tensions at the heart of the volume about the goals of the argumentative turn are probably inherent in an interdisciplinary applied science with pretensions to developing an empirical, theoretical, and normative 
critique of its subject matter. More interesting is the ambivalence in the analyses about, first, whether the argumentative turn is sufficient - or needs to be followed or supplemented by another turn (and, if so which); and, second, whether making an argumentative turn means essentially that an inquiry inspired by this turn takes argumentation (or closely related themes) as its entry-point or that an analysis should sooner or later include argumentation in order for the analysis to be complete. These questions are related but not identical. None of the contributions presented in this book are preoccupied exclusively with a description or internal critique of practical reasoning in one or another policy field: all provide further context and add further kinds of explanation, drawing on quite different theoretical approaches to do so. Nor do all the contributions take argumentation as their entry-point (beyond the politesse expected of an author or authors contributing to a volume on the argumentative turn). But all agree that argumentation matters and that taking argumentation seriously adds intellectual value to critical policy practice and analysis. I agree with this judgement. Turns are moments in the continuing reorganization and intellectual development of the social sciences (as in other fields) and their value persists long after they have produced new paradigms and turned into 'normal' science. The immediate returns from a social scientific turn depend on what occupied the intellectual mainstream beforehand - and, in the case at hand, the argumentative turn has proved very fruitful (see the editors' introduction for substantiation). But when a new approach becomes sedimented and serves mainly to generate normal science, new problems will provoke new turns and restless souls, marginal figures, and young tyros will be looking for answers to the anomalies, gaps, and weaknesses in the new turn. This can be seen already in the progress made in the two decades between the publication of The Argumentative Turn (Fischer and Forrester 1993) and the volume under review. The extent of the progress is reflected not only in their respective subtitles but also in the extent to which the main title of the 2012 collection does insufficient justice to the capacious range of studies included within it.

Acknowledgement: Some of the ideas advanced above benefitted from earlier discussions with Norman Fairclough about critical discourse analysis and practical reasoning. The usual disclaimers apply. It also draws on work during research funded by the UK's Economic and Social Research Council: grant RES-051-27-0303. 


\section{References}

Althusser, L., 1990. Philosophy and the Spontaneous Philosophy of the Scientists \& other Essays. London: Verso. <1967>

Debray, R., 1973. Prison Writings, London: Allen Lane.

Deutsch, K., 1963. The Nerves of Government. New York: Free Press.

Fairclough, N., 1989. Language and Power, 2nd ed., London: Longman.

Fairclough, I. and Fairclough, N., 2012. Political Discourse Analysis: a Method for Advanced Students. London: Routledge.

Fischer, F., and Forrester, J., eds., 1993. The Argumentative Turn in Policy Analysis, Durham, NC: Duke University Press.

Fischer, F., and Gottweiss, H., eds., 2012. The Argumentative Turn Revisited: Public Policy as Communicative Practice. Durham, NC: Duke University Press.

Glynos, J., and Howarth, D., 2007. Logics of Critical Explanation in Social and Political Theory. London: Routledge.

Jessop, B., 2009. Cultural political economy and critical policy studies. Critical Policy Studies 3 (3-4), 336-356. 